\title{
IN VITRO FERTILIZABILITY OF OOCYTES USING FRESH, FROZEN AND EPIDIDYMAL SPERMATOZOA FROM CROSSBRED BULLS IN THE TROPICS
}

\author{
Binoy S. Vettical \\ Department of Animal Reproduction, Gynaecology and Obstetrics \\ College of Veterinary and Animal Sciences, Mannuthy, Trichur \\ Email: binvsren@yahoo.com
}

\begin{abstract}
The objective of the study was to examine the fertilizability of bovine follicular oocytes from abattoir ovaries using fresh, frozen and epididymal spermatozoa from crossbred bulls in the tropics. Oocytes were cultured in maturation media TCM-199 containing 25mM HEPES, $1 \mathrm{mM}$ glutamine $\mathrm{L}, 2.2 \mathrm{mg} / \mathrm{mL}$ sodium bicarbonate, antibiotics, $22 \mu \mathrm{g} / \mathrm{mL}$ pyruvate, $1 \mu \mathrm{g} / \mathrm{mL}$ estradiol- $17 \beta, 0.5 \mu \mathrm{g} / \mathrm{mL}$ FSH and $0.06 \mathrm{IU}$ hCG and supplemented with $20 \%$ heat inactivated estrus cow serum (serum collected in early estrum) at $39^{\circ} \mathrm{C}$ temperature, $5 \% \mathrm{CO} 2$ tension with maximum humidity for 24 hours. Oocytes with maximum cumulus expansion were used for in vitro fertilization. Fresh, frozen and epididymal semen from crossbred bulls was used for in vitro fertilization as treatment $1(\mathrm{n}=1690)$, treatment $2(\mathrm{n}=1620)$ and treatment $3(\mathrm{n}=1710)$ respectively. Control group of oocytes (1680) were treated in the same protocol along with each treatment group of oocytes in separate in vitro fertilization drop without sperm injection. The in vitro fertilization medium consisted of Fert-TALP medium supplemented with $1 \mu \mathrm{M}$ epinephrine, $10 \mu \mathrm{M}$ hypotaurine, $20 \mu \mathrm{M}$ pencillamine and $0.56 \mu \mathrm{g} / \mathrm{ml}$ heparin. Culture conditions set for IVF were $39^{\circ} \mathrm{C}$ temperature, $5 \% \mathrm{CO} 2$ tension with maximum humidity. Oocytes showing sperm penetration evidence like presence of enlarged sperm head, male pronuclei with its accompanying sperm tail in the cytoplasm, oocytes with two pronuclei and a clear second polar body but without a sperm tail were considered as fertilized. None of the oocytes in control group showed cleavage due to parthenogenetic activation. Significantly higher results of fertilization rate $(\mathrm{p}<0.05)$ were observed when oocytes inseminated with epididymal spermatozoa than fresh ejaculated semen followed by frozen semen.
\end{abstract}

Key words: cattle; epididymal spermatozoa; fresh semen; frozen semen; in vitro fertilizability; Oocyte

\section{Introduction}

In vitro reproduction biotechnology has wide range applications with decisive advantages. In vivo methods requiring cumbersome procedures with high costs to recover the oocytes/early embryos, the in vitro techniques use abattoir ovaries which are easily available, inexpensive can provide a large number of oocytes in a short span to support various researches in the field of in vitro reproductive biotechnologies. In combination with ultrasound guided ovum pick up from live cows, this technology can maximize the number of progenies from elite animals and thereby to support the breeding bull production and genetic improvement through large-scale artificial insemination. Use of sexed semen in conjunction with in vitro embryo production is a potentially efficient means of obtaining offspring of predetermined sex (Romo et al., 2014). Progenies can be produced even from prepubertal and dead animals by IVF technique. Conservation of endangered species and rare livestock breeds are possible through in vitro fertilization techniques (Nicholls, 2012). In vitro production of embryos coupled with embryo transfer is a solution to the problem of low fertility of lactating dairy cows during hot periods of the year (Barusellia et al., 2011). More over the in vitro technology has relevance to assessing bull fertility (Morado et al., 2015).

The key to a successful in vitro fertilization is to promote sperm capacitation and to induce the acrosome reaction in vitro (Debby et al., 2012). Mammalian spermatozoa undergo a series of physiological events in the female reproductive tract prior to acquiring the fertilization capability (Austin, 1951; Chang, 1951). There are differences in the capacitation ability of ejaculated and epididymal spermatozoa. While capacitation of bovine epididymal spermatozoa can be achieved in a simple salt solution (Ball et al., 1983), ejaculated bovine spermatozoa do not undergo capacitation unless stimulated by capacitating agents (Parrish et al., 1986). Decapacitation factors of seminal plasma (Chang, 1951; Chung et al., 2011) may be responsible for these differences. However, freshly ejaculated and deep frozen bull spermatozoa do not differ in their capacitation ability in vitro (Essam et al., 2015). The objective of the present study was to examine the fertilizability of bovine follicular oocytes retrieved from 
abattoir ovaries using fresh, frozen and epididymal spermatozoa.

\section{Materials and Methods}

\section{Oocyte Retrieval and Processing}

Ovaries from crossbred cattle of Kerala were used for the study. Ovaries were dissected out from animals within 3060 minutes of slaughter and transported to the laboratory within 30-60 minutes in freshly prepared Dulbecco's phosphate buffered saline fortified with $100 \mathrm{IU} / \mathrm{ml}$ Benzyl penicillin and $100 \mu \mathrm{g} / \mathrm{ml}$ Streptomycin sulphate maintained at $36-38^{\circ} \mathrm{C}$. The ovaries were washed repeatedly in Dulbecco's buffered saline fortified with 100 IU/ml Benzyl penicillin and $100 \mu \mathrm{g} / \mathrm{ml}$ Streptomycin sulphate maintained at $36-38^{\circ} \mathrm{C}$, after trimming off the extraneous tissue. The final washing was done with Dulbecco's phosphate buffered saline supplemented with $0.5 \%$ BSA and maintained at $36-38^{\circ} \mathrm{C}$.

Oocytes were retrieved from ovaries by applying aspiration method. Surface follicles measuring $2-8 \mathrm{~mm}$ in size were aspirated with a sterile 18 gauge disposable needle connected to a $10 \mathrm{ml}$ disposable syringe .The retrieval process was carried out in COC handling media prepared with Dulbecco's phosphate buffered saline supplemented with $5 \%$ Day 0 estrus cow serum and $0.5 \%$ BSA and maintained at $37^{\circ} \mathrm{C}$. A total of 810 ovaries were used for oocyte retrieval in the study. After the isolation of oocytes by aspiration method, the medium containing oocytes were examined under the zoom stereomicroscope at 10x magnification for identification of oocytes. Identified oocytes were transferred into $35 \mathrm{~mm}$ petri dish containing $\mathrm{COC}$ handling media maintained at $37^{\circ} \mathrm{C}$. Oocytes were examined under 40x magnification of zoom stereomicroscope and grade I and gradeII categories were selected based on the number of layers of cumulus cells and ooplasm character (Grade I: More than 5 complete layers of cumulus cells and uniform granulation of ooplasm; Grade II: 3-5 complete layers of cumulus cells and uniform granulation of ooplasm ). Grade I and Grade II oocytes were combined together to form a new class namely culture grade oocytes and used for the study. Grade I and Grade II oocytes were put separately in labeled maturation media and further processing for in vitro maturation and in vitro fertilization study was done separately.

\section{In vitro Maturation}

Medium used for maturation of oocytes was freshly prepared Hepes modified TCM-199 (25 mMHepes) enriched with $22 \mu \mathrm{g} / \mathrm{ml}$ sodium pyruvate, $2.2 \mathrm{mg} / \mathrm{ml}$ sodium bicarbonate and antibiotics penicillin $\mathrm{G}$ sodium and streptomycin $0.5 \mathrm{mg} / \mathrm{ml}$ each. This medium was further supplemented with hormones, $1 \mu \mathrm{g} / \mathrm{ml}$ estradiol- $17 \beta$, $0.5 \mu \mathrm{g} / \mathrm{ml} \mathrm{FSH,} 0.06 \mathrm{IU}$ hCG and $20 \%$ heat-inactivated estrus cow serum prior to employing it for IVM. COCs were washed twice in maturation medium without hormones and transferred in groups of 5-10 into $100 \mu 1$ drops of maturation medium under silicone oil and allowed to complete incubation for a period of $24 \mathrm{~h}$ without any disturbance in the culture conditions. Culture conditions set for this study were $39^{\circ} \mathrm{C}$ temperature, $5 \% \mathrm{CO}_{2}$ tension with maximum humidity. After $24 \mathrm{~h}$ culture in maturation medium, all the oocytes in the culture drops were examined under zoom stereomicroscope for maturation changes such as expansion and mucification of cumulus cells. Oocytes after $24 \mathrm{~h}$ culture were classified based on the degree of cumulus cell expansion as per the classification of Hunter and Moore (1987) and oocytes with maximum degree of cumulus expansion (Grade 1) were selected for further in vitro fertilization studies.

\section{In vitro Fertilization}

At the end of in vitro maturation, the selected COCs were rinsed twice in Fert-TALP medium (Parrish et al., 1988). The in vitro fertilization medium consisted of Fert-TALP medium supplemented with $1 \mu \mathrm{M}$ epinephrine, $10 \mu \mathrm{M}$ hypotaurine, $20 \mu \mathrm{M}$ pencillamine and $0.56 \mu \mathrm{g} / \mathrm{ml}$ heparin (Khurana and Niemann, 2000).

Fresh ejaculated semen was obtained from healthy crossbred bulls and $50 \mu 1$ of fresh semen was layered over percoll density gradients and separated the motile spermatozoa. The frozen semen dose of crossbred bull was thawed in a $37^{\circ} \mathrm{C}$ water bath. The semen sample was applied on the top of the percoll gradient and motile spermatozoa were separated. Sperms from cauda epididymis of crossbred bulls were collected by gentle slicing and squeezing of the cauda epididymis and motile spermatozoa were separated by percoll density gradient separation. Semen was layered on a percoll gradient prepared by adding $2 \mathrm{ml}$ of $45 \%$ percoll on $2 \mathrm{ml}$ of $90 \%$ percoll in a $15 \mathrm{ml}$ centrifuge tube and centrifuged the semen overlaid on percoll gradient for 20 minutes at $700 \mathrm{x} \mathrm{g}$. The recovered sperm pellet was resuspended in sperm-TALP and again centrifuged at $300 \mathrm{x}$ $\mathrm{g}$ for 10 minutes. After removal of the supernatant, spermatozoa were resuspended in IVF medium (Khurana and Niemann, 2000). Concentration of the sperms in IVF medium was determined with haemocytometer and adjusted the concentration at $2 \times 10^{6} / \mathrm{ml}$ using IVF medium. The final concentration in fertilization droplet was adjusted to 15,000 to 20,000 sperms per oocytes.

Each category of matured oocyte (Grade I and Grade II Oocytes) after washing was loaded gently into separate in vitro fertilization drops and allowed to complete incubation for a period of $24 \mathrm{~h}$ without any disturbance in the culture conditions. Depending upon the availability, 5-10 matured oocytes were allowed into each fertilization drop. Culture conditions set for IVF were $39^{\circ} \mathrm{C}$ temperature, $5 \% \mathrm{CO}_{2}$ tension with maximum humidity (Khurana and Niemann, 2000). 


\section{Assessment of Fertilization}

Oocytes after 24 hour culture in fertilization medium were denuded by repeated pipetting and evaluated for evidence of sperm penetration. Oocytes showing sperm penetration evidence like presence of enlarged sperm head, male pronuclei with its accompanying sperm tail in the cytoplasm, oocytes with two pronuclei and a clear second polar body but without a sperm tail were considered as fertilized. Oocytes with more than two pronuclei and decondensed sperm heads were evaluated as polyspermic. Oocytes were examined under bright field of inverted phase contrast microscope and then stained with aceto orcein for the assessment of fertilization. The whole mount fixation of oocytes were carried out as per Chian et al. (1995) and fixed in acetic alcohol (acetic acid: ethanol, 1:3 v/v) for 48-72 $\mathrm{h}$ at room temperature. The slide taken out from fixative was examined under $20 \mathrm{X}$ magnification of zoom stereo microscope to locate the oocytes. Oocytes were stained with $1 \%$ orcein in $45 \%$ acetic acid. All the oocytes stained as above were examined under bright field of inverted phase contrast microscope at $200 \mathrm{X}-400 \mathrm{X}$ magnifications for evidence of sperm penetration.

\section{Experimental Design}

Culture grade oocytes matured in vitro were subjected to in vitro fertilization using fresh, frozen and epididymal spermatozoa in IVF medium as per the protocol of Khurana and Niemann(2000) and assessed the fertilization rates in the three groups separately. The effect of sources of spermatozoa on the yield of fertilized oocytes was assessed. Data on fertilization rate was statistically analyzed with one way ANOVA. P-value of less than 0.05 was considered statistically significant.

\section{Results}

\section{Effect of Sources of Spermatozoa on Fertilization Rate}

The fertilization rate obtained with total culture grade oocytes when fresh ejaculated, frozen and epididymal semen used for in vitro fertilization was $37.86 \pm 0.47$ $(640 / 1690), \quad 27.72 \pm 0.89(450 / 1620)$ and $44.51 \pm 0.57$ (760/1710) per cent respectively. There was significant difference observed between these three treatment groups $(\mathrm{P}<0.01)$. In vitro fertilization using epididymal spermatozoa showed significantly higher results when compared to IVF using fresh ejaculated semen, followed by IVF using frozen semen $(\mathrm{P}<0.01)$. The fertilization percentage obtained with grade I oocytes was $36.52 \pm 1.68$, $28.65 \pm 0.76$ and $46.53 \pm 1.32$ per cent when fresh, frozen and epididymal spermatozoa was used for in vitro fertilization. IVF using epididymal spermatozoa yielded significantly higher fertilization rate and IVF using frozen semen yielded lowest among the group when grade I oocytes alone considered for $\operatorname{IVF}(\mathrm{P}<0.01)$. Grade II oocytes yielded $45.00 \pm 5.63,23.89 \pm 3.03$ and $35.20 \pm 3.03$ per cent when fresh, frozen and epididymal spermatozoa were used for IVF. There was significantly higher results observed with fresh semen than with frozen semen in the yield of fertilized oocytes $(\mathrm{P}<0.01)$. But grade II oocytes alone are considered, there was no significant difference observed between epididymal source of spermatozoa and fresh semen or with frozen semen $(\mathrm{P}>0.05)$.

Table 1: Effect of sources of spermatozoa on the fertilization percentage and yield of fertilized oocyte per ovary (Morphological grade wise)

\begin{tabular}{|c|c|c|c|c|c|c|}
\hline \multirow{3}{*}{$\begin{array}{l}\text { Source of } \\
\text { Spermatozoa }\end{array}$} & \multicolumn{6}{|c|}{ Morphological grade of oocytes } \\
\hline & \multicolumn{2}{|c|}{ Grade I } & \multicolumn{2}{|c|}{ Grade II } & \multicolumn{2}{|c|}{ Total Culture grade oocytes } \\
\hline & $\begin{array}{l}\text { Percentage } \\
\text { oocytes showed } \\
\text { fertilization } \\
\text { signs }\end{array}$ & $\begin{array}{l}\text { Mean number of } \\
\text { oocytes per } \\
\text { ovary showed } \\
\text { fertilization } \\
\text { signs }\end{array}$ & $\begin{array}{l}\text { Percentage } \\
\text { oocytes showed } \\
\text { fertilization } \\
\text { signs }\end{array}$ & $\begin{array}{l}\text { Mean number of } \\
\text { oocytes per } \\
\text { ovary showed } \\
\text { fertilization } \\
\text { signs }\end{array}$ & $\begin{array}{l}\text { Percentage } \\
\text { oocytes showed } \\
\text { fertilization } \\
\text { signs }\end{array}$ & $\begin{array}{l}\text { Mean number of } \\
\text { oocytes per } \\
\text { ovary showed } \\
\text { fertilization } \\
\text { signs }\end{array}$ \\
\hline Fresh & $36.52 \pm 1.68^{\mathrm{a}}$ & $1.87 \pm 0.06^{\mathrm{a}}$ & $45.00 \pm 5.63^{\mathrm{a}}$ & $0.51 \pm 0.07^{\mathrm{a}}$ & $37.86 \pm 0.47^{\mathrm{a}}$ & $2.38 \pm 0.05^{\mathrm{a}}$ \\
\hline Frozen & $28.65 \pm 0.76^{\mathrm{b}}$ & $1.43 \pm 0.04^{\mathrm{b}}$ & $23.89 \pm 3.03^{\mathrm{b}}$ & $0.31 \pm 0.05^{\mathrm{b}}$ & $27.72 \pm 0.89^{b}$ & $1.73 \pm 0.07^{\mathrm{b}}$ \\
\hline Epididymal & $46.53 \pm 1.32^{\mathrm{c}}$ & $2.33 \pm 0.05^{\mathrm{c}}$ & $35.20 \pm 3.03^{\mathrm{a}}$ & $0.39 \pm 0.06^{\mathrm{a}}$ & $44.51 \pm 0.57^{\mathrm{c}}$ & $2.72 \pm 0.03^{\mathrm{c}}$ \\
\hline Total & $37.24 \pm 1.91$ & $1.87 \pm 0.09$ & $34.70 \pm 3.24$ & $0.40 \pm 0.04$ & $36.70 \pm 1.71$ & $2.28 \pm 0.10$ \\
\hline
\end{tabular}

Values with different superscripts $(\mathrm{a}, \mathrm{b}, \mathrm{c})$ in same column differ significantly $(\mathrm{P}<0.01)$ 


\section{Effect of Sources of Spermatozoa on the Yield of Fertilized Oocytes per Ovary}

The mean number of oocytes fertilized per ovary was $2.38 \pm 0.05(640 / 1690), 1.73 \pm 0.07(450 / 1620)$ and $2.72 \pm 0.03$ (760/1710), when fresh, frozen and epididymal spermatozoa were used for in vitro fertilization. There was significant difference observed between these three groups $(\mathrm{P}<0.01)$. Mean number of fertilized oocytes per ovary was significantly higher with epididymal spermatozoa than with fresh ejaculated semen. Similarly fresh ejaculated semen yielded significantly higher number of fertilized oocytes per ovary than with frozen semen. The mean number of fertilized oocytes per ovary obtained from grade I premature oocyte was $1.87 \pm 0.06,1.43 \pm 0.04$ and $2.33 \pm 0.05$ when fresh, frozen and epididymal spermatozoa was used for IVF. From grade II premature oocytes the yield of fertilized oocytes per ovary obtained was $0.51 \pm 0.07$, $0.31 \pm 0.05$ and $0.39 \pm 0.06$ when fresh, frozen and epididymal spermatozoa was used for IVF. A significant difference was observed between the source of spermatozoa with grade I premature oocytes $(\mathrm{P}<0.01)$. Significantly higher results obtained with epididymal source than with fresh semen, followed by frozen semen. But no significant difference was observed between these three groups with grade II premature oocytes $(\mathrm{P}>0.05)$.

\section{Discussion}

To the best of my knowledge, this is the first study carried out to compare simultaneously the effects of fresh, frozen and epididymal spermatozoa on fertilizability of crossbred bovine follicular oocytes. Fertilization rate obtained in the present study using fresh, frozen and epididymal spermatozoa was comparable to the results of many scientists and even better than the results of some workers (Saha et al., 2014). However, the overall results obtained was lower than the results of many workers, which might be due to multiple reasons like laboratory environment, breed and nutritional status of donor animals, level of expertise etc. Multiple factors like cytotoxic materials, water quality, gas composition, temperature, hydrogen ion concentration and osmolality of media and light exposure might be critical to the outcome of in vitro fertilization and embryo culture (Parrish, 2014).

There was significant difference observed between these three sources of spermatozoa on fertilization rate of bovine oocytes in vitro. Significantly higher results obtained with epididymal source than with fresh semen, followed by frozen semen when grade I and total culture grade oocytes were used for in vitro fertilization. There were significantly higher results observed with fresh semen than with frozen semen but there was no significant difference observed between fresh and epididymal sperm if grade II oocytes alone considered. The number of observations made with grade II oocytes was lower when compared to grade I and total culture grade oocytes and this might be the major reason for this variation. Fresh bull semen showed significantly higher fertilization rate when compared to frozen semen in the present study which is in agreement with the results of De Los Reyes et al. (2009) in canine. They reported that, fresh dog spermatozoa showed significantly higher penetration rate with both immature and in vitro matured canine oocytes in comparison to chilled or frozen sperm. Nagai et al. (1988) obtained significantly higher percentage of penetrated porcine oocytes in vitro with frozen epididymal spermatozoa when compared to the fertilization rate with frozen ejaculated spermatozoa which is also in agreement with the results of the present study in bovines.

Many studies were conducted on the effect of seminal plasma on fertilizability of bull spermatozoa in vitro (Katska et al., 1996; Leahy and de Graaf, 2012). Katska et al. (1996) studied the effect of seminal plasma on the in vitro fertilizability of bull spermatozoa. In their study, the in vitro embryo production efficiency with frozen-thawed epididymal spermatozoa was higher for fertilization, cleavage rate and blastocysts yield, when compared to the results with fresh ejaculated semen. Moreover, the seminal plasma deprived ejaculated sperm showed significantly more oocytes fertilized, cleaved and developed to the blastocyst stage when compared to ejaculate sperm. They opined that, the absence of seminal plasma during capacitation has appeared favorable to embryo production efficiency in vitro. The reversible antifertility effect of seminal plasma has been suggested as being due to inhibition of various acrosomal enzymes. Reports on several species including cattle suggest that seminal plasma contains factors that may influence male fertility (Leahy and de Graaf, 2012). Generally, these factors are believed to inhibit sperm capacitation, the acrosome reaction, or acrosomal enzymes and ultimately interfere with fertilization (Leahy and de Graaf, 2012). On the other hand, in many studies the positive role of seminal plasma in capacitation of bull sperm especially increasing the number of binding sites for heparin has been emphasized (Parrish, 2014; Leahy and de Graaf, 2012).

Contrary to these findings, (Henault et al., 1995) reported positive role of seminal plasma inducing the acrosome reaction in epididymal spermatozoa. The effect of seminal plasma on epididymal spermatozoa has been suggested as being due to heparin-binding proteins potentiating the ability of epididymal spermatozoa to be capacitated by heparin and to undergo acrosomal exocytosis at frequencies similar to those of epididymal sperm. Many scientists recommended the use of frozen cauda epididymal spermatozoa for mass embryo production of unknown genetic value (Katska et al., 1996; El-Badry et al., 2015).

\section{Conclusion}

In conclusion, the present data indicate that epididymal spermatozoa retrieved from abattoir bulls could be 
efficiently used for in vitro fertilization of in vitro matured bovine oocytes equal to or even better than fresh ejaculated or frozen thawed semen. The in vitro fertilizing ability of cauda epididymal spermatozoa can be utilized for in vitro production of embryos from wild animals, endangered species and other animals in which collection of ejaculated semen is a difficult task.

\section{Acknowledgement}

I am grateful to Dr. E. Nanu, Dean, College of Veterinary and Animal Sciences, Mannuthy, Kerala Agricultural University for the facilities provided for the research work. I express my sincere thanks to Dr. T. Sreekumaran Professor and Head (Rtd) and Dr. V. Vijayakumaran, Professor and Head, Department of Animal Reproduction, Gynaecology and Obstetrics for their valuable guidance.

\section{References}

Austin CR (1951) Observations on the penetration of the sperm into the mammalian egg. Aust. J. Sci. Res. 4(4): 581-596

Ball GD, Leibfried ML, Lenz RW, Ax RL, Bavister BD and First NL (1983) Factors affecting successful in vitro fertilization of bovine follicular oocytes. Biol. Reprod. 28: 717-725. DOI: $10.1095 /$ biolreprod28.3.717

Barusellia PS, Ferreiraa RM, Salesa JNS, Gimenesa LU, Sa Filhoa MF, Martinsa CM, Rodriguesb CA and Boc GA (2011) Timed embryo transfer programs for management of donor and recipient cattle. Theriogenology 76(9): 15831593. DOI: 10.1016/j.theriogenology.2011.06.006

Chang MC (1951) Fertilizing capacity of spermatozoa deposited in the fallopian tubes. Nature 168: 697-698. DOI: $10.1038 / 168697 \mathrm{~b} 0$

Chian RC, Okuda K and Niwa K (1995) Influence of cumulus cells on in vitro fertilization of bovine oocytes derived from in vitro maturation. Anim. Reprod. Sci. 38: 37-48. DOI: $10.1038 / 168697 b 0$

Chung HL, Robert K L, Yuh-Ming H, Shian-Ling C, Ying-Jie C, Wei-Chao C, Shau-Ping L and Sheng H L (2011) SERPINE2, a Serine Protease Inhibitor Extensively Expressed in Adult Male Mouse Reproductive Tissues, May Serve as a Murine Sperm Decapacitation Factor. Bio. Repro. 84: 514-525. DOI: 10.1095/biolreprod.110.085100

De Los Reyes M, Palomino J, de Lange J, Anguita C and Barros C (2009) In vitro sperm penetration through the zona pellucida of immature and in vitro matured oocytes using fresh, chilled and frozen canine semen. Anim. Reprod. Sci. 110: 37-45. DOI: 10.1016/j.anireprosci.2007.12.010

Debby I, Maya F and Haim B (2012) Mechanism of sperm capacitation and the acrosome reaction: role of protein kinases. Asian J. Androl. 14(6): 816-821. DOI: 10.1038/aja.2012.81

El-Badry DA, Scholkamy TH, Abeer M A and Karima GhM M (2015) Assessment of freezability and functional integrity of dromedary camel spermatozoa harvested from caput, corpus and cauda epididymides. AJVS 44(1): 147-158. DOI: $10.5455 /$ ajvs. 178345

Essam A, Youichirou H, Takuya U, Koushi M, Mostafa S, Foad F, Ismail EK, Kazuo K and Tetsuma M (2015) Desalted and lyophilized bovine seminal plasma delays induction of the acrosome reaction in frozen-thawed bovine spermatozoa in response to calcium ionophore. Theriogenology $\quad \mathbf{8 3}(2)$ : $175-85$. DOI: 10.1016/j.theriogenology.2014.09.004

Henault MA, Killian GJ, Kavanaugh JF and Griel LC Jr (1995) Effect of accessory sex gland fluid from bulls of differing fertilities on the ability of cauda epididymal sperm to penetrate zona-free bovine oocytes. Biol. Reprod. 52: 390397. DOI: 10.1095/biolreprod52.2.390

Hunter AG and Moor RM (1987) Stage-dependent effects of inhibiting ribonucleic acids and protein synthesis on meiotic maturation of bovine oocytes in vitro. J. Dairy Sci. 70: 1646-1651. DOI: 10.3168/jds.S0022-0302(87)801923

Katska L, Rynska B and Smorag Z (1996) Effect of seminal plasma on the in vitro fertilizability of bull spermatozoa. Anim. Reprod. Sci. 44: 23-31. DOI: 10.1016/03784320(96)01495-9

Khurana NK and Niemann H (2000) Effects of cryopreservation on glucose metabolism and survival of bovine morulae and blastocysts derived in vitro or in vivo. Theriogenology $\mathbf{5 4}$ : 313-326. DOI: 10.1016/S0093-691X(00)00351-4

Leahy T and de Graaf SP (2012) Seminal plasma and its effect on ruminant spermatozoa during processing. Reprod. Domest. Anim. 47(Suppl 4): 207-213. DOI: 10.1111/j.1439-0531.2012.02077.x

Morado S, Pereyra V, Breininger E, Sara R and Cetica P (2015) Study of Sperm Evaluation Parameters to Estimate Cryopreserved Bovine Semen Fertility. Austin J. Vet. Sci. \& Anim. Husb. 2(1): 1005

Nagai T, Takahashi T, Masuda H, Shioya Y, Kuwayama M, Fukushima M, Iwasaki S and Hanada A (1988) In-vitro fertilization of pig oocytes by frozen boar spermatozoa. $J$. Reprod. Fertl. 84: 585-591. DOI: 10.1530/jrf.0.0840585

Nicholls H (2012) Endangered species: Sex and the single rhinoceros. Nature 485: 566-569. DOI: 10.1038/485566a

Parrish JJ (2014) Bovine In vitro fertilization: In vitro oocyte maturation and sperm capacitation with heparin. Theriogenology $\quad \mathbf{8 1}(1)$ : $1010-1016 . \quad$ DOI: 10.1016/j.theriogenology.2013.08.005

Parrish JJ, Susko-Parrish JL, Leibfried-Rutledge ML, Critser ES, Eyestone WH and First NL (1986) Bovine in vitro fertilization with frozen-thawed semen. Theriogenology 25: 591-600. DOI: 10.1016/0093-691X(86)90143-3

Parrish JJ, Susko-Parrish JL, Winer MA and First NL (1988) Capacitation of bovine sperm by heparin. Biol. Reprod. 38: 1171-1180. DOI: 10.1095/biolreprod38.5.1171

Romo S, Castaneda S, Hernandez CA, Mendoza JH, Trejo FJ, Zamora J, Fernandez JE, Ducolomb Y and Kjelland ME (2014) IVF-derived crossbred embryos produced with 
sexed semen and transferred in pairs to Bos Taurus $\times$ Bos indicus cows and heifers. Repro. Fert. \& Dev. 27(1): 246247. DOI: $10.1071 /$ RDv27n1Ab315
Saha S, Khandoker MAMY, Asad LY, Reza AMMT and Hoque A (2014) Effect of Fresh and Frozen Semen on in vitro Fertilization and Subsequent Development of Goat Embryos. IJAS 4(2): 325-330 